\title{
PENGEMBANGAN E-GOVERNMENT DI DKI JAKARTA (STUDI PORTAL RESMI PROVINSI DKI JAKARTA)
}

\author{
Muhammad Amfahtori Wijarnoko', Muhammad Agiel Asy'ari², Abdur Rouf ${ }^{3}$ \\ ${ }^{1,2,3}$ Program Studi Sistem Informasi, Universitas Trunojoyo Madura \\ e-mail: ${ }^{1}$ 170441100012@ @student.trunojoyo.ac.id, ${ }^{2} 170441100033 @$ student.trunojoyo.ac.id, \\ 3170441100037@student.trunojoyo.ac.id.
}

\begin{abstract}
Abstrak
Provinsi DKI Jakarta telah menerapkan adanya egovernment menjadi sarana komunikasi dengan masyarakat untuk menunjang kegiatan pemerintahan provinsi untuk lebih memudahkan pelayanan terhadap stakeholder yang berkepentingan seperti masyarakat dan pihak swasta menggunakan kemajuan teknologi informasi. Kualitas portal web tersebut dari segi informasi, relevansi, dan ketersediaannya tentu akan menjadi sorotan bagi para stakeholder karena status Jakarta sebagai Ibu Kota Negara dan ini menuntut untuk penerapan egovernment yang terbaik. Sehingga perlu adanya pengembangan yang berkelanjutan dengan tetap memperhatikan kesiapan infrastruktur pendukung, serta sumber daya manusia pegawai pemerintahan dan masyarakat. Dalam penelitian ini menggunakan metode studi literatur yang digunakan untuk pembelajaran dan pemahaman informasi yang terkait dengan pokok pembahasan penelitian. Hasil yang didapat dari pembahasan ini yaitu pengembangan egovernment merupakan proses eksplorasi yang melalui langkah-langkah mempersiapkan, mematangkan, memantapkan, dan terakhir memanfaatkan sesuatu yang di dalamnya ada aspek pendukung dalam pemerintah, kesiapan jumlah sumber daya, dan manfaatnya berdampak langsung ke masyarakat. Pengembangan egovernment pada portal resmi Provinsi DKI Jakarta perlu dilakukan evaluasi.
\end{abstract}

Kata kunci: pengembangan, egovernment, pelayanan publik, pemerintah provinsi

\begin{abstract}
DKI Jakarta Province has implemented the existence of government as a means of communication with the community to support the activities of the provincial government to facilitate services to interested stakeholders such as the public and the private sector using information technology advancements. The quality of the web portal in terms of information, relevance, and availability will certainly be a highlight for stakeholders because of Jakarta's status as the Capital City of the State and this demands for the best implementation of government. So that there is a need for sustainable development while paying attention to the readiness of supporting infrastructure, as well as the human resources of government employees and the community. In this study using the literature study method used for learning and understanding of information related to the subject of research. The results obtained from this discussion are the development of eggovernment is an exploration process through the steps of preparing, maturing, consolidating, and finally utilizing something in which there are supporting aspects in government, the readiness of the amount of resources, and its benefits have a direct impact on society. Development of government in the official portal of DKI Jakarta Province needs to be evaluated.
\end{abstract}

Keywords: development, egovernment, public service, provincial government

\section{PENDAHULUAN}

Kemudahan dalam mengakses informasi pemerintahan menjadi aspek penting sebagai pelayanan publik yang baik kepada masyarakat. Upaya yang dilakukan pemerintah untuk mewujudkan hal tersebut salah satunya dengan memanfaatkan perkembangan teknologi informasi. Dalam pengaplikasiannya, teknologi informasi yang telah digunakan untuk kegiatan pemerintahan dikenal dengan istilah E-Government yang fungsinya memberikan dampak peningkatan efisiensi pelayanan publik dan mewujudkan pemerintahan yang demokratis. 
Di Provinsi DKI Jakarta telah menerapkan adanya egovernment menjadi sarana komunikasi dengan masyarakat untuk menunjang kegiatan pemerintahan provinsi. Dapat kita ketahui salah satu misi Pemerintah Provinsi DKI Jakarta yaitu menjadikan Jakarta tempat wahana aparatur negara yang berkarya, mengabdi, melayani, serta menyelesaikan berbagai permasalahan kota dan warga, secara efektif, meritokratis dan beritegritas. Ini menunjukkan bahwa egovernment dapat menjadi penunjang utama dalam pelayanan pemerintahan secara efektif di Provinsi DKI Jakarta.

Contoh upaya yang telah diterapkan oleh Pemerintah Provinsi DKI Jakarta yang terkait dengan egovernment adalah pembuatan Portal Resmi Pemerintahan Provinsi DKI Jakarta dengan alamat www.jakarta.go.id. Portal web yang dimiliki pemerintah Provinsi DKI Jakarta berisi informasi untuk mengenal Jakarta lebih dekat bagi mereka yang berkepentingan baik dalam urusan bisnis atau urusan pemerintahan lainnya. Kualitas portal web tersebut dari segi informasi, relevansi, dan ketersediaannya tentu akan menjadi sorotan bagi para stakeholder karena status Jakarta sebagai Ibu Kota Negara dan ini menuntut untuk penerapan egovernment yang terbaik. Sehingga perlu adanya pengembangan yang berkelanjutan dengan tetap memperhatikan kesiapan infrastruktur pendukung, serta sumber daya manusia pegawai pemerintahan dan masyarakat. Berdasarkan data dari Katadata.co.id, DKI Jakarta ditempatkan sebagai provinsi dengan hasil penilaian E-Government teratas pada tahun 2015 dan hasil ini berhasil dipertahankan posisinya dalam jangka waktu dua tahun berturut-turut.

10 Provinsi dengan e-Government Terbaik

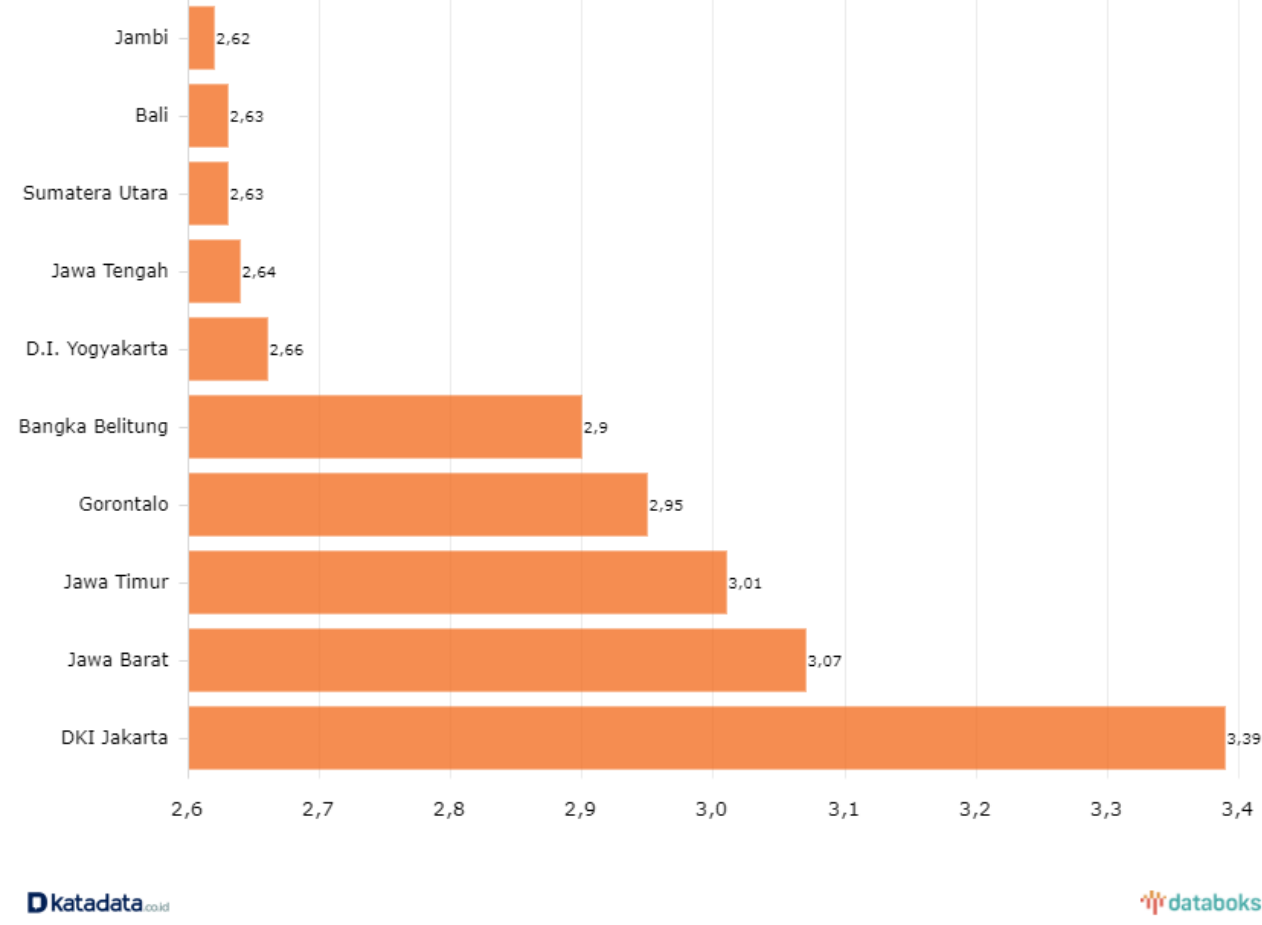

Gambar 1. Grafik 10 Provinsi dengan E-Government terbaik Tahun 2015

Sumber: https://databoks.katadata.co.id

Berdasarkan penjelesan di atas, maka dapat dirumuskan permasalahannya yaitu bagaimana pengembangan dalam penerapan E-Government di DKI Jakarta pada Portal Resmi Provinsi DKI Jakarta. 


\section{TINJAUAN PUSTAKA}

\subsection{Electronic Government}

Electronic Government adalah salah satu mekanisme dalam interaksi yang baru antara aparat pemerintahan (baik di level daerah atau pusat) dengan masyarakat dan orang-orang lain yang memiliki kepentingan (stakeholder) dimana interaksi ini melibatkan pemanfaatan adanya teknologi informasi yang berujuan meningkatkan kualitas pelayanan pemerintahan yang berjalan [1]. Pada dasarnya Electronic Government merupakan upaya menerapkan teknologi informasi untuk memperudah mendekatkan para stakeholder dengan pemerintah. Implementasi dari egovernment dipercaya dapat memperbaiki dan meningkatkan kinerja dalam pengelolaan pemerintahan di Indonesia [2].

Konsep pelaksanaan Electronic Government menurut Instruksi Presiden No. 3 Tahun 2003 tentang Kebijakan dan Strategi Nasional Pengembangan egovernment menjelaskan bahwa egovernment merupakan upaya untuk mengembangkan penyelenggaraan kepemerintahan yang berbasis (menggunakan) elektronik dalam rangka meningkatkan kualitas layanan publik secara efektif dan efisien. Melalui pengembangan egovernment dilakukan penataan sistem manajemen dan proses kerja di lingkungan pemerintah dengan mengoptimasikan pemanfaatan teknologi informasi [3].

\subsection{Pengembangan $E$-Government}

Pengembangan E-Government menurut Inpres 3 tahun 2003 Tentang Kebijakan dan Strategi Nasional Pengembangan E-Government adalah merupakan upaya untuk mengembangkan penyelenggaraan kepemerintahan yang berbasis (menggunakan) elektronik dalam rangka meningkatkan kualitas layanan publik secara efektif dan efisien.

Tahapan pengembangan E-Government menurut Inpres 3 tahun 2003:

1. Persiapan

a. Pembuatan situs web sebagai media informasi dan komunikasi pada setiap lembaga.

b. Sosialisasi situs web untuk internal dan publik.

2. Pematangan

a. Pembuatan situs web informasi publik yang bersifat interaktif.

b. Pembuatan antar muka keterhubungan dengan lembaga lain.

3. Pemantapan

a. Pembuatan situs web yang bersifat transaksi pelayanan publik.

b. Pembuatan interoperabilitas aplikasi dan data dengan lembaga lain.

4. Pemanfaatan

Pembuatan aplikasi untuk pelayanan yang bersifat Government to Government (G2G), Government to Business (G2B), Government to Consumers $(G 2 C)[4]$.

\subsection{Penelitian Terdahulu}

Penelitian yang dilakukan oleh Lely P.D. Tampubolon dari Program Studi Teknik Informatika, Fakultas Teknologi Informasi, Perbanas Institute, Jakarta pada tahun 2016 yang berjudul "Pemeringkatan E-Government Indonesia (Pegi) dan Pemanfaatan Teknologi Informasi di DKI Jakarta" menjelaskan bahwa pewujudan konsep kota Jakarta smart city (smart Gov, smart people, smart mobility, smart 
economy, smart living dan smart environment) memanfaatkan teknologi informasi di Indonesia, khususnya DKI Jakarta memiliki ekosistem yang telah ditetapkan oleh Kominfo (network, device dan application). Pemanfaatan teknologi informasi berdampak positif terhadap peningkatan kinerja DKI Jakarta dalam mewujudkan Jakarta Smart City [5].

Penelitian yang dilakukan oleh Marudur Pandapotan Damanik dan Erisva Hakiki Purwaningsih pada tahun 2017 yang berjudul "E-Government dan Aplikasinya di Lingkungan Pemerintah Daerah (Studi Kasus Kualitas Informasi Website Kabupaten Bengkalis Propinsi Riau)" memperoleh hasil bahwa secara umum kualitas informasi website Pemerintah Kabupaten Bengkalis sudah cukup baik. Kekurangan yang dapat mengurangi nilai kualitas informasi ada pada dimensi kelengkapan informasi, yaitu adanya beberapa tautan yang menuju ke halaman kosong [6].

Penelitian yang dilakukan oleh Ni Ketut Dewi Ari Jayanti dari Program Studi Sistem Informasi, STMIK STIKOM Bali pada tahun 2017 yang berjudul "Kajian Analisa: Penerapan dan Pengembangan E-Government pada Pemerintah Propinsi Bali". Dalam penelitian ini menjelaskan bahwa Penyusunan rumusan pengembangan egovernment yang optimal pada pemerintah provinsi Bali disusun berdasarkan analisa sebab akibat, analisa kebutuhan serta analisa keputusan yang dilakukan. Dalam penyusunan rumusan pengembangan egovernment ini melibatkan subsystems, yaitu: a. Sistem egovernment, merupakan aplikasi-aplikasi elektronik pada pemerintah; $b$. Leadership, merupakan dukungan dari pemegang kekuasaan (pemerintah); c. Entitas egovernment, merupakan organisasi yang mengatur penerapan dan pengembangan egovernment; d. User, dalam hal ini bisa masyarakat dan pemerintah; e. Infrastruktur, merupakan teknik arsitektur yang menghubungkan dan mengintegrasikan tingkat pemerintahan dan SKPD [7].

Dari literatur review yang telah dijelaskan diatas maka dapat diambil intisarinya bahwa banyak dampak positif dari adanya pemanfaatan egovernment di lingkungan pemerintahan. Kekurangan dalam kualitas informasi mungkin saja dialami dalam implementasinya namun ini dapat diatasi dengan merumuskan pengembangan egovernment yang tersetruktur dan terencana dengan melibatkan subsistemnya.

\section{METODOLOGI PENELITIAN}

Dalam penelitian ini menggunakan metode studi literatur yang digunakan untuk pembelajaran dan pemahaman informasi yang terkait dengan pokok pembahasan penelitian. Literatur yang digunakan dalam penelitian ini didapatkan dari berbagai sumber seperti buku literatur, dan artikel jurnal penelitian.

Metode pengumpulan data dalam penelitian ini diperoleh melalui observasi dan pembahasan analisis terhadap portal resmi Provinsi DKI Jakarta yang sudah ada. Analisis ini nantinya dapat diperoleh data-data yang memiliki relevansi pada penelitian yang dilakukan. 


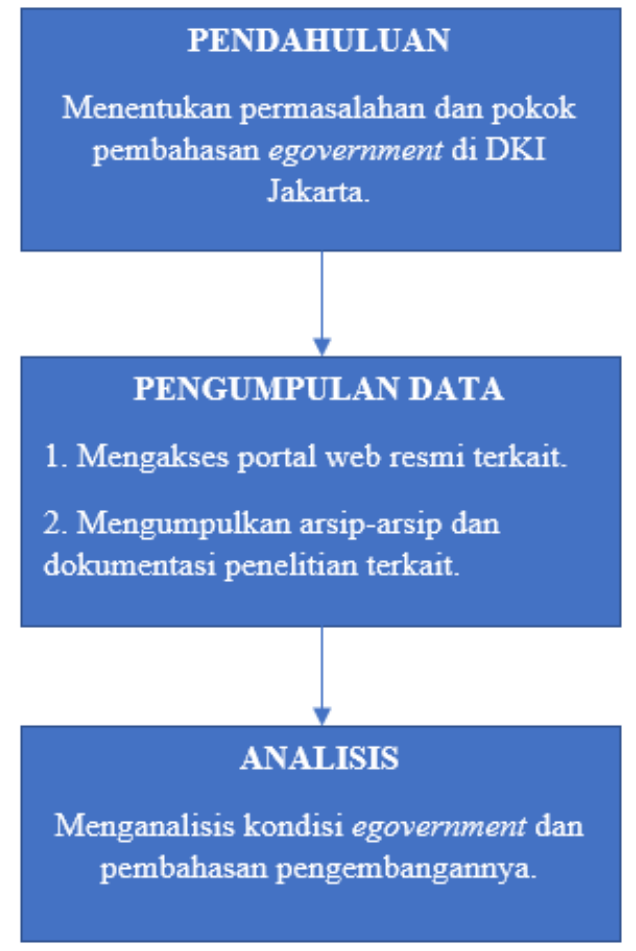

Gambar 2. Alur penelitian

\section{HASIL DAN PEMBAHASAN}

\subsection{Hasil Penelitian}

Portal Resmi Provinsi DKI Jakarta memiliki domain jakarta.go.id yang dikelola langsung oleh Dinas Komunikasi, Informatika dan Statistik Pemprov DKI Jakarta. Portal Resmi Provinsi DKI Jakarta sudah ada sejak tahun 1995, dan telah mengalami banyak perubahan dari tahun ke tahun dimana perubahan terakhir dilaksanakan pada tahun 2020. Perubahan dilakukan dari berbagai aspek termasuk desain tampilan dan konten untuk meningkatkan kualitas website dan informasi yang ada di dalamnya.



Gambar 3. Tampilan Portal Resmi Provinsi DKI Jakarta

Sumber: https://jakarta.go.id 
Konten yang ada pada Portal Resmi Provinsi DKI Jakarta bersifat statis dan umum. Halaman depan website memiliki beberapa pilihan menu yaitu mengenal jakarta, datang dan kunjungi, bisnis jakarta, kanal pengaduan, website terkait, layanan publik, informasi keuangan, infografis, ensiklopedi, perangkat daerah, hidup di jakarta, dan TGUPP.

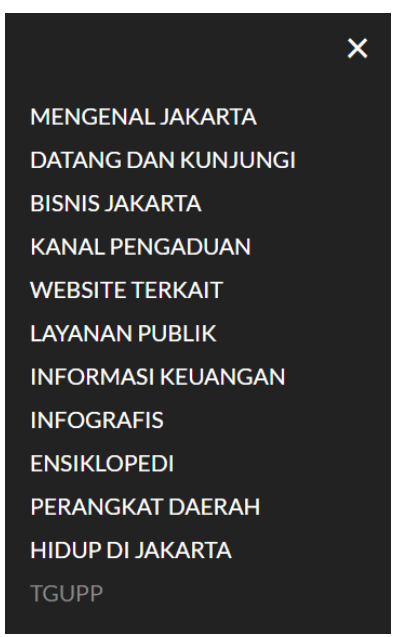

Gambar 4. Pilihan Menu Portal Resmi Provinsi DKI Jakarta

Sumber: https://jakarta.go.id

Selain mengakses melalui menu, beberapa tautan (link) juga tersedia langsung pada halaman website untuk mengakses info sosialisasi, portal jakarta smart city, LHKPN, dan informasi pengumuman lainnya. Secara visual dapat dilihat di gambar berikut ini.

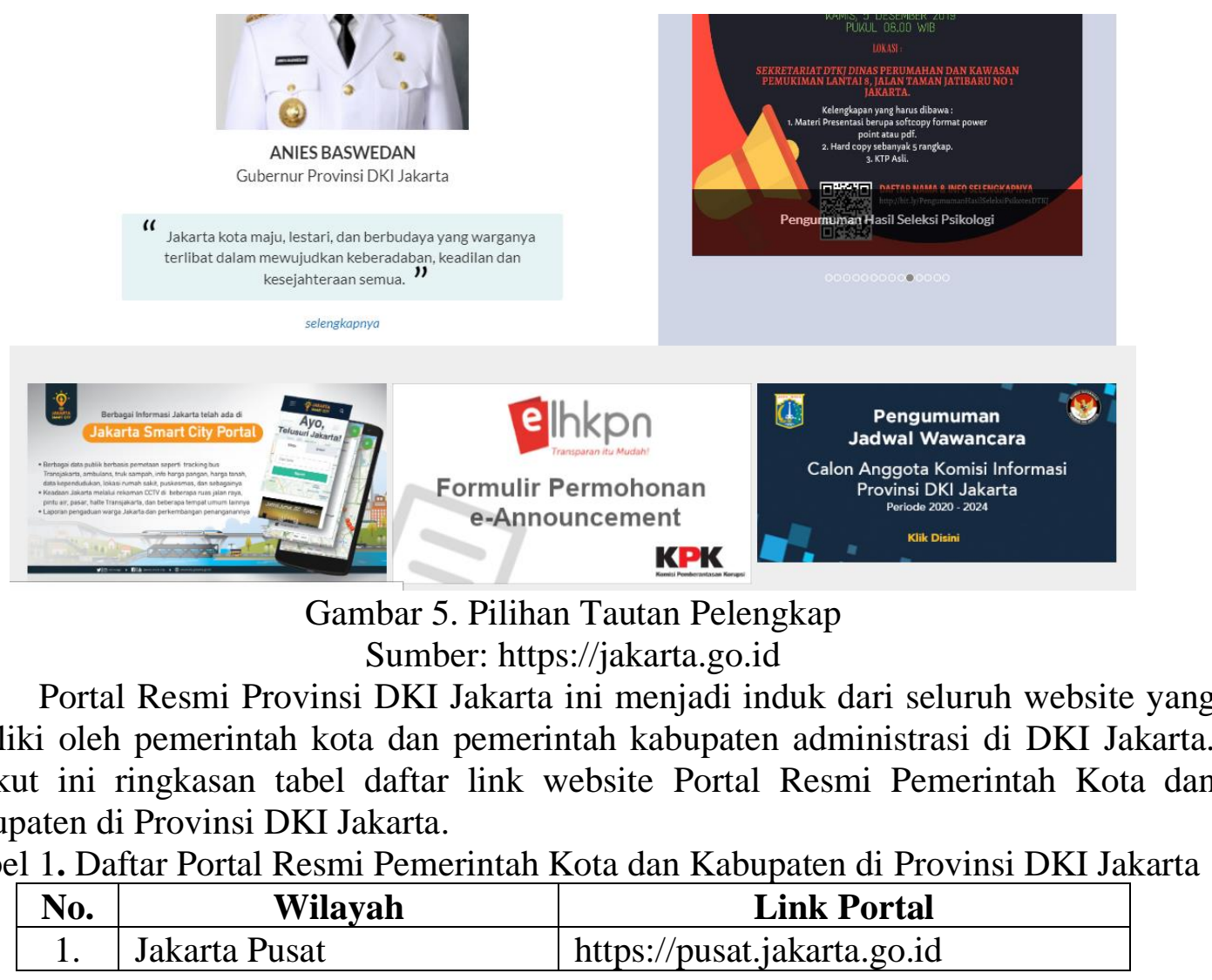




\begin{tabular}{|c|l|l|}
\hline 2. & Jakarta Timur & https://timur.jakarta.go.id \\
\hline 3. & Jakarta Selatan & https://selatan.jakarta.go.id \\
\hline 4. & Jakarta Barat & https://barat.jakarta.go.id \\
\hline 5. & Jakarta Utara & https://utara.jakarta.go.id \\
\hline 6. & Kepulauan Seribu & https://pulauseribu.jakarta.go.id \\
\hline
\end{tabular}

Dengan pengelolaan egovernment yang terpusat dari Kota/Kabupaten ke Provinsi ini, DKI Jakarta dinilai sudah baik dalam menjalankan pemerintahan dan menentukan kebijakan berbasis teknologi informasi. Hal ini memudahkan para warga masyarakat, khususnya Jakarta untuk mengakses segala informasi mengenai pemerintahan ataupun mendapatkan pelayanan dengan lebih cepat dan terpadu.

\subsection{Pembahasan}

Penelitian ini bertujuan untuk menggambarkan penerapan e-government dengan menjelaskan kualitas informasi Portal Resmi Provinsi DKI Jakarta. Kualitas informasi dalam website egovernment memiliki peranan penting karena akan memberikan dampak luas bagi masyarakat. Informasi yang disampaikan oleh kanal resmi pemerintah akan dianggap valid oleh masyarakat, sehingga apabila informasi yang disampaikan tidak benar akan berakibat pada menurunnya kepercayaan publik pada pemerintah.

Adapun dlihat dari perspektif kualitas informasi, dan ketersediaan pada Portal Resmi Provinsi DKI Jakarta memiliki penilaian yang cukup baik. Mengembangkan egovernment merupakan sesuatu yang kompleks dan sulit untuk dilakukan. Meskipun pada kenyataannya sistem Information and Communication Technology (ICT) pada suatu daerah sudah baik namun mereka juga masih khawatir dengan masalah teknologi dan budaya. Hal-hal yang dirasa perlu untuk dipahami adalah harus diketahui dengan jelas alasan mengapa egovernment harus diterapkan sehingga perlu didefinisikan secara jelas visi dari penerapan dan pengembangan egovernment tersebut. Yang tidak kalah pentingnya adalah harus diketahui faktor-faktor yang mempengaruhi pengembangan egovernment, tahapan-tahapan egovernment yang perlu diimplementasikan serta model egovernment yang optimal yang dapat diterapkan Pemerintah Provinsi DKI Jakarta.

Permasalahan yang ada saat ini dapat dinarasikan sebagai berikut:

1. Performance

Dalam proses pelaksanaan proyek egovernment, tidak semua berhasil dilaksanakan. Hal ini disebabkan karena kurangnya dukungan dari pemegang kekuasaan dalam pengembangan egovernment. Beberapa negara yang telah berhasil dalam mengembangkan dan menerapkan egovernment adalah Kolombia, Kenya, India, Malaysia, Amerika, Palestina, Korea Selatan. Sedangkan negara yang tidak berhasil dalam mengembangkan dan menerapkan egovernment adalah Mozambique dan Uganda. Performance diukur berdasarkan manfaat yang telah dirasakan masyarakat dan pemerintah dalam menerapkan egovernment.

2. Information

Pengamatan yang dilakukan terhadap situs-situs egovernment dan pengalaman-pengalaman beberapa negara dalam mengembangkan dan menerapkan yang ada saat ini menampilkan informasi yang tidak relevan, karena tidak diupdate secara berkala.

3. Economics 
Karena belum adanya tahapan-tahapan yang dijadikan acuan dalam pengembangan egovernment, sehingga penerapan egovernment masih belum berhasil dilaksanakan. Sebagai contoh, misalnya tahap awal proyek pengembangan sistem adalah perencanaan. Pada tahap awal ini ditentukan ruang lingkup proyek, kebutuhan dan batasan, partisipan proyek, biaya, jadwal. Hal ini perlu ditentukan untuk menilai kelayakan dari suatu proyek pengembangan egovernment.

4. Control and Security

a. Tidak adanya kontrol dan monitoring dalam penerapan egovernment.

b. Kurangnya kesediaan dan kemampuan masyarakat dalam penggunaan ICT.

c. Keamanan data dan jaringan masih belum memadai.

5. Efficiency

Hingga saat ini, pemerintah mengalami kesulitan dalam mengupdate informasi pada situsnya. Hal ini dikarenakan belum maksimalnya sarana yang memudahkan proses tersebut.

6. Services

Pelayanan pemerintah terhadap masyarakat hingga saat ini belum optimal.

Kurangnya sosialisasi dan program-program insentif pemerintah dalam bidang egovernment.

Pengembangan egovernment dalam pelayanan publik Pada Portal Resmi Provinsi DKI Jakarta didukung oleh beberapa elemen berikut:

\section{a. Elemen Support}

Saat ini belum ada perencanaan berkala dalam konsep pengembangan egovernment yang disepakati bersama. Sosialisasi egovernment yang dilakukan oleh Pemerintah Provinsi DKI Jakarta dilakukan dengan cara dimuatkan ke dalam program-program yang dijalankan dan disematkan di portal yang telah disediakan.

b. Elemen Capacity

Elemen Capacity berkaitan dengan tersedianya sumber daya. Sumber daya yang harus terpenuhi adalah sumber daya finansial, sumber daya manusia, dan infrastruktur. Berkaitan dengan sumber daya finansial Pemerintah Provinsi DKI tidak memiliki kendala dalam keuangan karena telah di anggaran yang dibuat cukup untuk memenuhi kebutuhan.

c. Elemen Value

Berdasarkan hasil penelitian menunjukkan bahwa website yang dimiliki oleh Pemerintah Provinsi DKI Jakarta telah dikelola secara maksimal. Dalam pengelolaannya terdapat standar yang harus diperhatikan yang telah ditetapkan oleh Kementerian Kominfo.

d. Elemen Willingness

Kemauan masyarakat dalam menggunakan teknologi informasi menjadi faktor penting dalam pengembangan egovernment. Karena akan siasia saja pengembangan egovernment dilakukan secara baik tetapi tidak ada masyarakat yang menggunakannya. Dari hasil lapangan menunjukkan bahwa 
banyak masyarakat menggunakan teknologi informasi secara baik, seperti pelaku usaha yang menggunakan teknologi informasi sebagai media pemasaran, menghitung keuangan usahanya, dan lain sebagainya.

e. Elemen Local Culture

Dari hasil lapangan menunjukkan bahwa Kondisi budaya Pemerintah Provinsi DKI Jakarta, sebagian besar pegawainya mampu menggunakan media internet untuk memperudah pekerjaannya. Tetapi tidak dipungkiri juga bahwa sebagian lainnya juga masih menggunakan internet sebagai media untuk hiburan semata. Local culture yang ada dalam masyarakat menjadi hambatan dalam pengembangan egovernment karena sebagian masyarakat belum sepenuhnya melek teknologi informasi. Hal tersebut berdasarkan pada masyarakat yang lebih nyaman menggunakan metode berinteraksi dengan orang lain secara langsung.

\section{KESIMPULAN}

Pengembangan egovernment merupakan proses eksplorasi yang melalui langkah-langkah mempersiapkan, mematangkan, memantapkan, dan terakhir memanfaatkan sesuatu yang di dalamnya ada aspek pendukung dalam pemerintah, kesiapan jumlah sumber daya, dan manfaatnya berdampak langsung ke masyarakat. Pengembangan egovernment pada portal resmi Provinsi DKI Jakarta perlu dilakukan evaluasi. Pengembangan infrastruktur juga perlu dilakukan secara bertahap dan berkelanjutan. Pengembangan egovernment di portal resmi Provinsi DKI Jakarta masih memiliki beberapa kekurangan seperti ketidakstabilan performance yang harus diperbaiki agar para pengguna seperti masyarakat dan pihak-pihak lain yang menggunakan portal resmi Provinsi DKI Jakarta merasa nyaman dalam mengakses segala informasi yang telah disediakan. Dan, kinerja penggunaan egovernment di DKI Jakarta tetap menjadi yang terbaik.

\section{DAFTAR PUSTAKA}

[1] Angraini. (2015). Penerapan E-Government Ditingkat Kabupaten (Case Study Kabupaten Pelalawan Riau). Jurnal Sistem Informasi (JSI). 5(2). 815-825. Retrieved from http://ejournal.unsri.ac.id/index.php/jsi/index.

[2] Indrayani, Etin. 2016. E-Government: Konsep, Implementasi dan Perkembangannya di Indonesia (Buku Literatur MK E-government). Sumedang: Institut Pemerintahan Dalam Negeri.

[3] Prasetyo AA, Nurcahyanto H, Rihandoyo. -. Analisis Pengembangan E-Government di Kota Semarang (Studi Website Resmi Kota Semarang). Semarang: Jurusan Administrasi Publik Fakultas Ilmu Sosial dan Ilmu Politik Universitas Diponegoro.

[4] Angguna YP, Gani AYA, Sarwono. -. UPAYA PENGEMBANGAN EGOVERNMENT DALAM PELAYANAN PUBLIK PADA DINAS KOPERASI DAN UKM KOTA MALANG. PEMERINGKATAN E-GOVERNMENT INDONESIA (PEGI) DAN PEMANFAATAN TEKNOLOGI INFORMASI DI DKI JAKARTA. Jurnal Administrasi Publik (JAP), 3(1), 80-88.

[5] Tampubolon LPD. 2016. Jurnal Sistem Informasi (JSI). 8(2). 1121-1132.

[6] Damanik MP, Purwaningsih EH. 2017. E-GOVERNMENT DAN APLIKASINYA DI LINGKUNGAN PEMERINTAH DAERAH (Studi Kasus Kualitas Informasi Website Kabupaten Bengkalis Propinsi Riau). JURNAL STUDI KOMUNIKASI DAN MEDIA. 21(2). 151-164. 
[7] Jayanti NKDA. 2017. Kajian Analisa: Penerapan dan Pengembangan e-Government pada Pemerintah Propinsi Bali. Citec Journal. 4(2). 141-150. 